\title{
Dehydrogenation of bioethanol using Cu nanoparticles supported on Ndoped ordered mesoporous carbon
}

\author{
Pulikkal Thumbayil, Rouzana; Christensen, David Benjamin; Mielby, Jerrik Jørgen; Kegnæs, Søren
}

Published in:

ChemCatChem

Link to article, DOI:

$10.1002 /$ cctc. 202000883

Publication date:

2020

Document Version

Peer reviewed version

Link back to DTU Orbit

Citation (APA):

Pulikkal Thumbayil, R., Christensen, D. B., Mielby, J. J., \& Kegnæs, S. (2020). Dehydrogenation of bioethanol using Cu nanoparticles supported on Ndoped ordered mesoporous carbon. ChemCatChem, 12(22), 5644-5655. https://doi.org/10.1002/cctc.202000883

\section{General rights}

Copyright and moral rights for the publications made accessible in the public portal are retained by the authors and/or other copyright owners and it is a condition of accessing publications that users recognise and abide by the legal requirements associated with these rights.

- Users may download and print one copy of any publication from the public portal for the purpose of private study or research.

- You may not further distribute the material or use it for any profit-making activity or commercial gain

- You may freely distribute the URL identifying the publication in the public portal 


\title{
ChemCatChem
}

The European Society Journal for Catalysis

\section{F. Chemistry Europe}

European Chemical Societies Publishing

\begin{abstract}
Accepted Article
Title: Dehydrogenation of bioethanol using Cu nanoparticles supported on $\mathrm{N}$-doped ordered mesoporous carbon

Authors: Rouzana Pulikkal Thumbayil, David Benjamin Christensen, Jerrik Mielby, and Soeren Kegnaes

This manuscript has been accepted after peer review and appears as an Accepted Article online prior to editing, proofing, and formal publication of the final Version of Record (VoR). This work is currently citable by using the Digital Object Identifier (DOI) given below. The VoR will be published online in Early View as soon as possible and may be different to this Accepted Article as a result of editing. Readers should obtain the VoR from the journal website shown below when it is published to ensure accuracy of information. The authors are responsible for the content of this Accepted Article.
\end{abstract}

To be cited as: ChemCatChem 10.1002/cctc.202000883

Link to VoR: https://doi.org/10.1002/cctc.202000883 


\title{
Dehydrogenation of bioethanol using $\mathrm{Cu}$ nanoparticles supported on $\mathrm{N}$-doped ordered mesoporous carbon
}

\author{
Rouzana Pulikkal Thumbayil, ${ }^{[a]}$ David Benjamin Christensen, ${ }^{[a]}$ Jerrik Mielby, ${ }^{*[a]}$ and Søren Kegnæes*[a]
}

[a] Dr. R.P. Thumbayil, D.B. Christensen, Dr. J. Mielby, Prof. S. Kegnæs Department of Chemistry,

Technical University of Denmark

Kemitorvet 207, 2800 Kgs. Lyngby (Denmark)

E-mail: skk@kemi.dtu.dk

Supporting information for this article is given via a link at the end of the document.

\begin{abstract}
Carbon supported $\mathrm{Cu}$ nanoparticles have a remarkable selectivity towards the catalytic dehydrogenation of bioethanol to acetaldehyde, which is an interesting alternative to the preparation from ethylene. In this work, we prepared a series of catalysts comprised of $\mathrm{Cu}$ nanoparticles supported on $\mathrm{N}$-doped ordered mesoporous carbons to investigate the catalytic effect of nitrogen content. Our study shows that $\mathrm{N}$-doping has a significant effect on the dispersion of $\mathrm{Cu}$ nanoparticles and that the highest content of $\mathrm{N}$ results in the highest activity. Furthermore, we show that the combined effects of strong metal-support interactions and nanoconfinement is an effective method to prevent thermal and steam induced sintering. In contrast, we find no evidence that $\mathrm{N}$-doping activates the substrate or change the rate-determining step. At $260^{\circ} \mathrm{C}$, the best catalyst results in $>99 \%$ selectivity and a site-time yield of $175 \mathrm{~mol}_{\text {acetaldehyde }} / \mathrm{mol}_{\mathrm{Cu}} / \mathrm{h}$. Under these conditions, the catalysts are stable for more than $12 \mathrm{~h}$ using an aqueous solution of $10 \%$ ethanol as feed.
\end{abstract}

\section{Introduction}

Considering the critical need to reduce the emission of $\mathrm{CO}_{2}$, the chemical industry must gradually rely on renewable energy and biomass rather than fossil fuel resources. One such example could be the synthesis of acetaldehyde via dehydrogenation or partial oxidation of bioethanol, ${ }^{[1,2]}$ which is an interesting alternative to the preparation from ethylene (the Wacker process). Acetaldehyde is used for the production of acetic acid, ethyl acetate, acetic anhydride, pyridine, vinyl acetate and other commercially important products. ${ }^{[3,4]}$ In the past, the dehydrogenation of ethanol to acetaldehyde was typically performed at $260-290^{\circ} \mathrm{C}$ using copper chromite catalysts. Unfortunately, these catalysts suffer from co-formation of several by-products, including ethyl acetate, acetic acid and crotonaldehyde. ${ }^{[5-7]}$ Because of their high selectivity towards acetaldehyde, supported copper catalysts, such as $\mathrm{Cu}-\mathrm{SiC},{ }^{[5]} \mathrm{Cu} / Z$ Zeolites, ${ }^{[8]} \mathrm{Cu}-\mathrm{SiO}_{2}$, ${ }^{[9,10]} \mathrm{Cu}-\mathrm{Al}_{2} \mathrm{O}_{3},{ }^{[11]} \mathrm{Cu}-\mathrm{ZnO}-\mathrm{Al}_{2} \mathrm{O}_{3},{ }^{[12]} \mathrm{Cu} /$ carbon, ${ }^{[13]}$ or $\mathrm{Cu} / \mathrm{GO}$, ${ }^{[14]}$ have therefore sparked renewed interest. $\mathrm{Cu}$ supported on carbon materials are currently among the most selective catalysts ${ }^{[13,15]}$ because of the relatively inert carbon surface, which limits secondary reactions such as esterification, aldol condensation or ketonization. ${ }^{[9]}$ However, the weak metalsupport interactions and the relatively low melting point of copper make the carbon-supported catalysts particularly prone to sintering. Furthermore, copper easily gets oxidized in air, which results in fast deactivation. ${ }^{[16-20]}$ Encapsulation of nanoparticles to a confined space has proven to be a promising way to stabilize nanoparticle during catalytic reactions. [19] Additionally, the inert surface of mesoporous carbon can help minimize side reactions to increase the selectivity towards acetaldehyde. ${ }^{[9,13]}$

It has previously been shown that $\mathrm{N}$-doping can increase the metal-support interactions between the metal nanoparticles and the carbon support. ${ }^{[20,21]}$ For instance, Bulushev et al. reported $\mathrm{N}$-doping of carbon and the use of the material as a support for Cu nanoparticles in the catalytic decomposition of formic acid. [22] The use of graphiticnitrogen for the stabilization of $\mathrm{Cu}$ nanoparticles in different $\mathrm{N}$-doped carbon supports such as polyacrylonitrile-based porous carbon (PPC), commercial microporous carbon (CMC) are also reported for dehydrogenation of ethanol to acetaldehyde. Morales et al. reported $\mathrm{Cu}$ supported on graphite and reduced graphene oxide functionalized with nitrogen groups for bioethanol as feed. ${ }^{[14]}$ However, the nature and catalytic effect of $\mathrm{N}$-doping on activity and stability of $\mathrm{Cu}$ nanoparticles are still not fully understood.

In order to investigate the effect of $\mathrm{N}$-doping, we supported Cu-nanoparticles on three ordered mesoporous carbon materials with different $\mathrm{N}$-content. We then tested the catalysts for the Cu-catalyzed dehydrogenation of bioethanol to acetaldehyde to compare the catalytic activity, selectivity and stability over time. The influence of N-doping on the activation energy of catalysts and reaction mechanism were also studied using Arrhenius plot and in-situ DRIFTS. Additionally, the catalytic activity of commercially available $\mathrm{Cu}$ supported on activated carbon (3Cu/AC) were also studied to compare the performance of the synthesized catalysts. In contrast to the ordered mesoporous carbon support, the carbon support in $3 \mathrm{Cu} / \mathrm{AC}$ is microporous. ${ }^{[23,24]}$

Three ordered mesoporous carbon with different $\mathrm{N}$ loading were synthesized by changing the carbon-nitrogen precursors. They are abbreviated as NMC-0, NMC-2 and NMC-7, where 0,2 and 7 refers to the approximate percentage of nitrogen. Figure 1 shows the synthesis of the three ordered mesoporous carbons with different carbonnitrogen precursors. Synthesis of NMC-7 uses 3aminophenol (3-AMP) and hexamethylenetetramine (HMTA) as the precursors responsible for the high $\mathrm{N}$-content of 


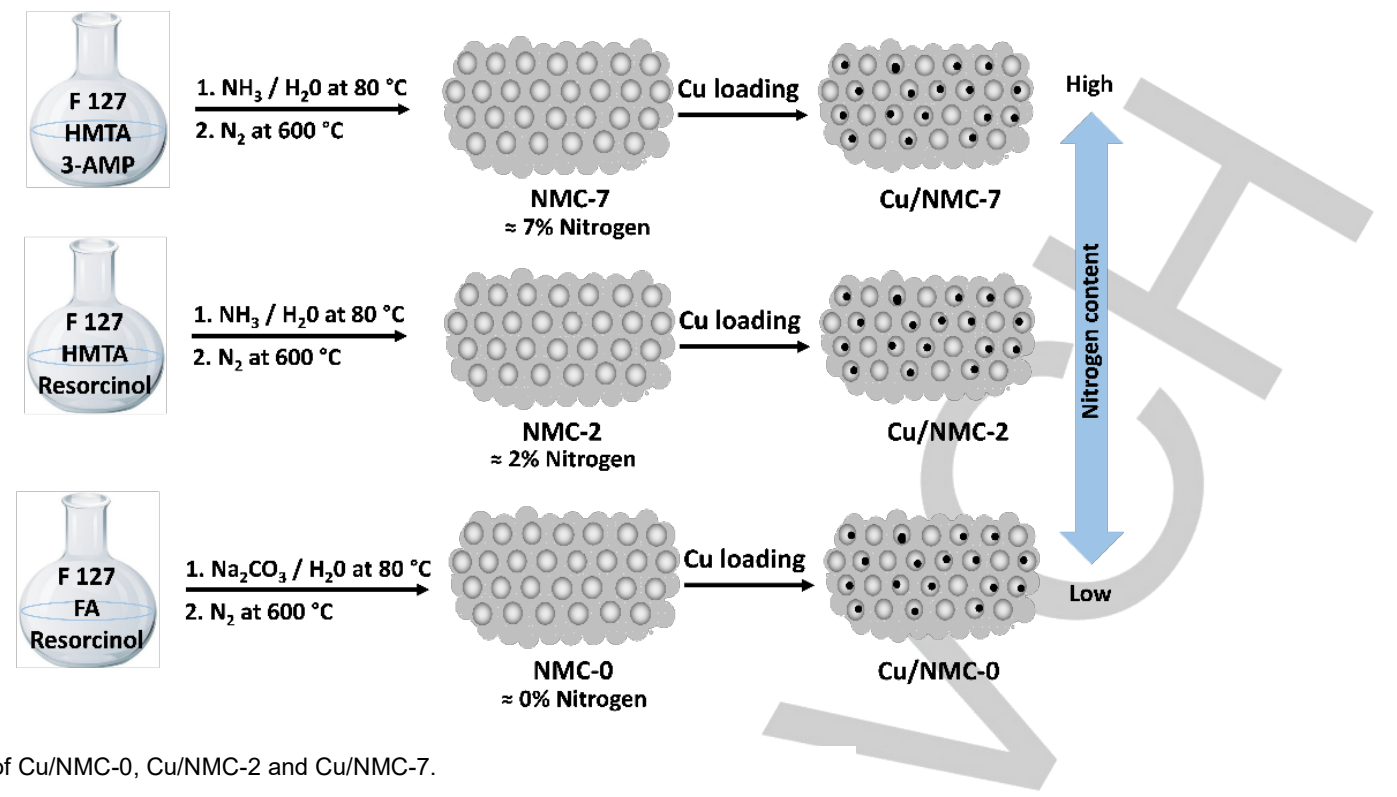

Figure 1. Synthesis route of Cu/NMC-0, Cu/NMC-2 and Cu/NMC-7.

ordered mesoporous carbon. ${ }^{[25]}$ In NMC-2 synthesis, 3-AMP was replaced with resorcinol (with no $\mathrm{N}$-functional group) whereas both 3-AMP and HMTA was exchanged with $\mathrm{N}$-free reagents such as resorcinol, formaldehyde (FA) and $\mathrm{Na}_{2} \mathrm{CO}_{3}$ for the synthesis of NMC-0.

\section{Results and Discussion}

Commercially available copper on activated carbon support was used as a reference to compare the performance of the synthesized materials. Figure 2 shows the $\mathrm{N}_{2}$ physisorption isotherms of the as-synthesized mesoporous carbon supports and copper on activated carbon. As expected, the physisorption isotherm of the NMCs showed the characteristic type IV isotherm with a $\mathrm{H} 4$ hysteresis loop, which is typically associated with capillary condensation in mesoporous materials. ${ }^{[26,27]}$ The hysteresis loop closes around $\mathrm{p} / \mathrm{p}_{0}=0.3,0.38$ and 0.45 for NMC-0,

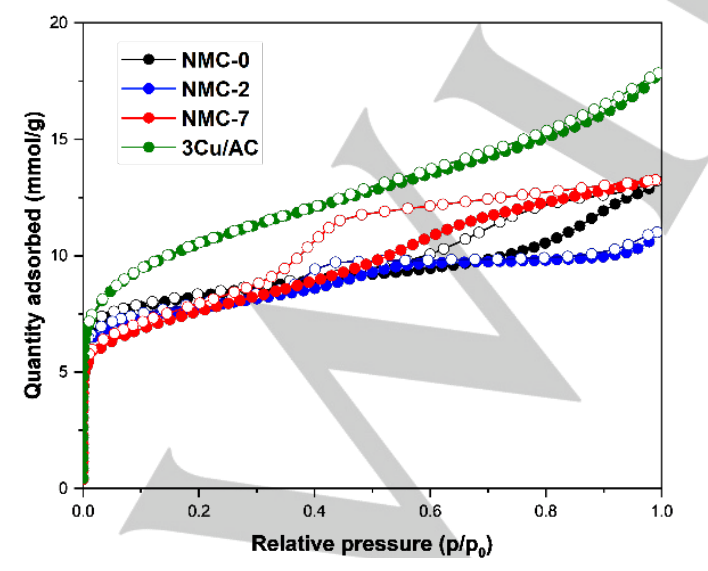

Figure 2. $\mathrm{N}_{2}$ Physisorption isotherm of mesoporous carbon supports and $3 \mathrm{Cu} / \mathrm{AC}$.
NMC-2 and NMC-7 respectively. The high uptake at low $\mathrm{p} / \mathrm{p}_{0}$ shows the presence of microporous textures in ordered mesoporous carbon. [28] Physisorption analysis of the commercial copper on activated carbon catalyst (3Cu/AC) showed a typical type I isotherm with no significant mesoporosity. As expected, the specific surface area and porosity decreased for all catalysts after loading with $\mathrm{Cu}$ nanoparticles, see Table 1 . The surface area increased in the order of NMC-7 $<$ NMC-0 $<$ NMC-2, which indicates some

Table 1. $\mathrm{N}_{2}$ Physisorption Data for synthesised materials.

\begin{tabular}{llll}
\hline Catalyst & $\begin{array}{l}\mathbf{V}_{\text {total }}{ }^{[\mathrm{a}]} \\
\left(\mathbf{c m}^{3} \mathbf{g}^{-1}\right)\end{array}$ & $\begin{array}{l}\mathbf{V}_{\mathbf{m i c r}^{[\mathrm{b}]}} \\
\left(\mathbf{c m}^{3} \mathbf{g}^{-1}\right)\end{array}$ & $\begin{array}{l}\mathbf{S}_{\mathrm{BET}}{ }^{[\mathrm{c}]} \\
\left(\mathbf{m}^{2} \mathbf{g}^{-1}\right)\end{array}$ \\
\hline NMC-0 & 0.411 & 0.17 & 590 \\
3Cu/NMC-0 & 0.388 & 0.12 & 512 \\
NMC-2 & 0.478 & .11 & 602 \\
1Cu/NMC-2 & 0.458 & 0.09 & 542 \\
3Cu/NMC-2 & 0.296 & 0.15 & 504 \\
8Cu/NMC-2 & 0.275 & 0.15 & 476 \\
NMC-7 & 0.529 & 0.09 & 578 \\
1Cu/NMC-7 & 0.349 & 0.11 & 484 \\
3Cu/NMC-7 & 0.323 & 0.10 & 413 \\
8Cu/NMC-7 & 0.319 & 0.08 & 400 \\
3Cu/AC & 0.584 & 0.16 & 811 \\
\hline
\end{tabular}

[a] $\mathrm{V}_{\text {total }}$ determined from the adsorption isotherm branch at around $\mathrm{p} / \mathrm{p}_{0}=0.95$.

[b] $\mathrm{V}_{\text {micro }}$ calculated by the t-plot method.

[c] $S_{B E T}$ calculated from BET surface area plot. 
changes in the textural properties of the different NMC $[29,20]$ The pore size distribution of all materials is shown in Figure S1. The results show that NMC-2 and NMC-7 are quite similar with a narrow pores size distribution around 5-6 $\mathrm{nm}$, while NMC-0 has a broader size distribution around 10 $\mathrm{nm}$ in diameter.

Table 2 shows the carbon and nitrogen content of the support materials determined by elemental analysis. Nitrogen content of NMC-7 is approximately $9.4 \mathrm{wt} \%$ while that of NMC-0 is $0.4 \mathrm{wt} \%$. The metal loading in the catalyst were measured by ICP-OES to confirm that the amount of copper precursor used during the synthesis was appropriate. The result confirms the copper loading in the three materials, $3 \mathrm{Cu} / \mathrm{NMC}-0,3 \mathrm{Cu} / \mathrm{NMC}-2$ and $3 \mathrm{Cu} / \mathrm{NMC}-7$ to be $2.94,2.95$, 2.8 wt $\%$ respectively.

Table 2. Elemental $\mathrm{CHN}$ analysis of mesoporous carbon support.

\begin{tabular}{lccc}
\hline Catalyst & $\begin{array}{c}\text { Carbon } \\
(\%)\end{array}$ & $\begin{array}{c}\text { Nitrogen } \\
(\%)\end{array}$ & $\begin{array}{c}\text { Hydrogen } \\
(\%)\end{array}$ \\
\hline 3Cu/NMC-0 & 89.9 & 0.4 & 9.7 \\
3Cu/NMC-2 & 86.1 & 1.5 & 12.4 \\
3Cu/NMC-7 & 84.1 & 9.4 & 6.5 \\
\hline
\end{tabular}

Figure 3(a) shows the XRD pattern of the prepared catalysts and $3 \mathrm{Cu} / \mathrm{AC}$ and Figure $3(\mathrm{~b})$ zoom in the $\mathrm{Cu}(111)$ peak in three as-synthesized catalysts. Materials with same copper loading (3wt\%), 3Cu/NMC-0, 3Cu/NMC-2, 3Cu/NMC7 and $3 \mathrm{Cu} / \mathrm{AC}$ shows the characteristic XRD pattern of $\mathrm{Cu}(111)$ plane at $2 \theta=43.2^{\circ}$. However, the intensity of the peak decreases with increase in the $\mathrm{N}$-content of mesoporous carbon. We attribute this to the highly dispersed copper particle on the N-doped carbon. ${ }^{[30,31]}$ In addition to $\mathrm{Cu}(111)$ peak, a weak diffraction peak was observed corresponding to $\mathrm{Cu}_{2} \mathrm{O}(111)$ for $3 \mathrm{Cu} / \mathrm{NMC}-0,3 \mathrm{Cu} / \mathrm{NMC}-2$ and $3 \mathrm{Cu} / \mathrm{AC}$. However, no XRD pattern were observed for mesoporous carbon and therefore confirms the amorphous nature of the ordered mesoporous carbons (Figure S2). Figure S3 shows the XRD pattern of various metal loading on NMC-2 and NMC-7 such as 1 and 8 wt\% of copper. In general, the intensity of the $\mathrm{Cu}(111)$ peak at $43.2^{\circ}$ increases

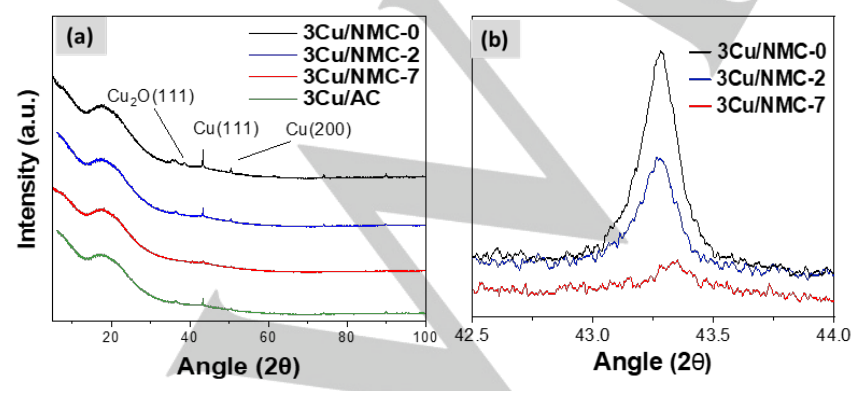

Figure 3. a) XRD Pattern of $3 \mathrm{Cu} / \mathrm{NMC}-0,3 \mathrm{Cu} / \mathrm{NMC}-2,3 \mathrm{Cu} / \mathrm{NMC}-7$ and $3 \mathrm{Cu} / \mathrm{AC}$ b) $\mathrm{Cu}(111)$ zoom in.
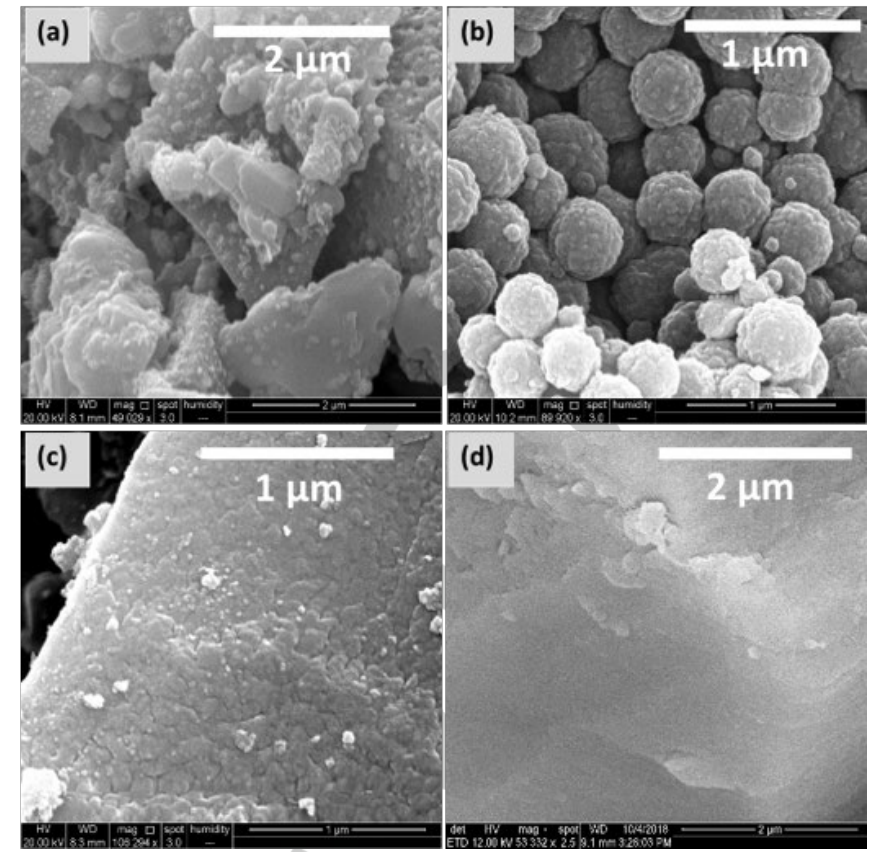

Figure 4. SEM Images of a) 3Cu/NMC-0, b) 3Cu/NMC-2, c) 3Cu/NMC-7 and d) $3 \mathrm{Cu} / \mathrm{AC}$.

with the copper loading. The morphology of the materials is analyzed using SEM and is shown in Figure 4. Interestingly, the morphology of the NMC-2 carbon support showed a uniform and spherically shaped mesoporous carbon structures, which are quite different from NMC-0 and NMC7. This difference in the structure of NMCs is likely due to the difference in the precursors of polymers. The SEM image for $3 \mathrm{Cu} / \mathrm{AC}$ showed even structures without any visible mesoporosity or channel like structures.

The TEM images of as-synthesized materials in Figure 5 shows uniform and highly ordered mesopores throughout the materials. The measured pore widths are in the range of 5-6 $\mathrm{nm}$ for NMC-7, NMC-2 and 8-10 nm for NMC-0, which agree well with the results from the $\mathrm{N}_{2}$ physisorption analysis. The TEM image of $3 \mathrm{Cu} / \mathrm{AC}$ in Figure 5(d) shows the particles with average size of $22.1 \mathrm{~nm}$. Figure $5(\mathrm{a}-\mathrm{c})$ shows the TEM images of 3Cu/NMC-0, 3Cu/NMC-2 and 3Cu/NMC-7. With the exception of a few large particles on the external surface of the catalysts, the images show a high dispersion of $\mathrm{Cu}$ particles distributed throughout the ordered mesoporous carbons. The size distribution based on the measurement of $>200$ Cu particles are shown in Figure S4. Most particles in $3 \mathrm{Cu} / \mathrm{NMC}-7$ are small with an average particle size of around $6.4 \mathrm{~nm}$. The TEM image of $3 \mathrm{Cu} / \mathrm{NMC}-0$ shows both small and large nanoparticles with an average size of particles around $12.4 \mathrm{~nm}$. The copper nanoparticles in 3Cu/NMC-2 has an average size of $11.5 \mathrm{~nm}$. In general, the average size of the nanoparticles increases in the order 3Cu/NMC-7 < $3 \mathrm{Cu} / \mathrm{NMC}-2<3 \mathrm{Cu} / \mathrm{NMC}-0$. The HAADF image of $3 \mathrm{Cu} / \mathrm{NMC}-$ 7 shown in Figure S5 confirms the confinement of uniformly distributed copper nanoparticles owing to the high nitrogen content. The TEM images for the other materials such as 

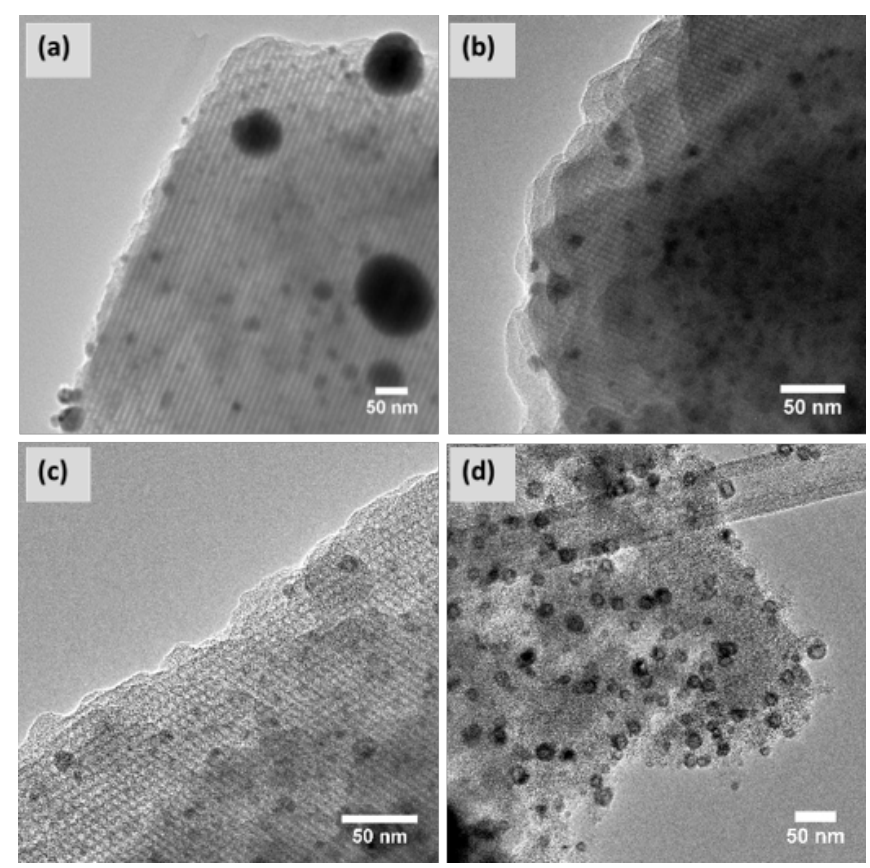

Figure 5. TEM Images of a) 3Cu/NMC-0, b) 3Cu/NMC-2, c) 3Cu/NMC-7 and d) $3 \mathrm{Cu} / \mathrm{AC}$
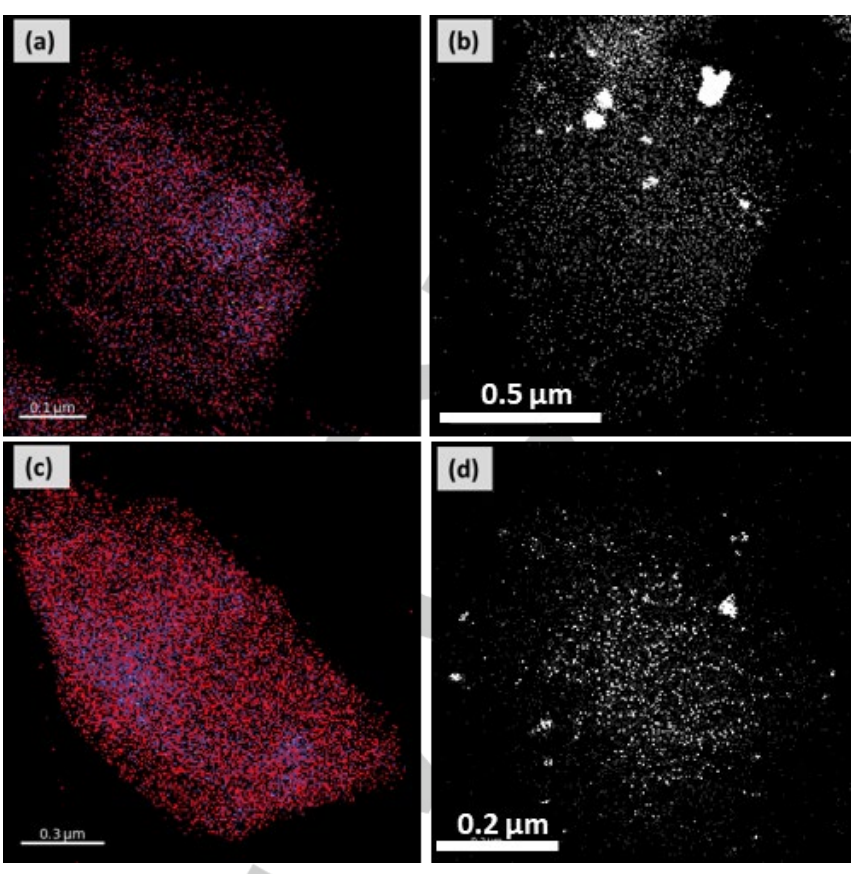

Figure 6. EDX Element distribution of a) N in NMC-2 b) Cu in 3Cu/NMC-2 c) $\mathrm{N}$ in NMC-7 and d) Cu in 3Cu/NMC-7.
1Cu/NMC-2, 8Cu/NMC-0, 8Cu/NMC-2, 1Cu/NMC-7 and $8 \mathrm{Cu} / \mathrm{NMC}-7$ are shown in Figure S5.

The reducibility of the copper particles on 3Cu/NMC-0, 3Cu/NMC-2 and 3Cu/NMC-7 as compared to 3Cu/AC was investigated by $\mathrm{H}_{2}-\mathrm{TPR}$, see Figure $\mathrm{S} 6$. The $\mathrm{H}_{2}-\mathrm{TPR}$ profile show differences in the shape, number and temperature range of the peaks for the three materials. The difference in the shape of the peaks indicates the presence of more than one type of copper species in the materials. ${ }^{[32]}$ Notably, the TPR profile of the materials showed peaks below $300{ }^{\circ} \mathrm{C}$. This may be explained by the presence of small and welldispersed copper nanoparticles that are easily reduced. ${ }^{[32,33]}$ In contrast, the high-temperature peak above $400{ }^{\circ} \mathrm{C}$ in TPR of $3 \mathrm{Cu} / \mathrm{AC}$ indicates the presence of large copper oxide nanoparticles that are difficult to reduce. ${ }^{[34]}$

Figure 6 shows the surface elemental composition of $3 \mathrm{Cu} / \mathrm{NMC}-2$ and $3 \mathrm{Cu} / \mathrm{NMC}-7$ as determined by EDX analysis. Figure 6(a) and 6(c) shows the $\mathrm{N}$ mapping in NMC2 and NMC-7 respectively, where the $\mathrm{N}$ signals are evenly distributed on the surface of ordered mesoporous carbon. However, the intensity of $\mathrm{N}$ signal is relatively less in NMC-2 in comparison to NMC-7 and this can be attributed to the nitrogen loading in each sample. Figure 6(b) and 6(d) shows the Cu mapping in NMC-2 and NMC-7, respectively, where the intensity of the $\mathrm{Cu}$ photopeak is uniform for both $3 \mathrm{Cu} / \mathrm{NMC}-2$ and $3 \mathrm{Cu} / \mathrm{NMC}-7$.

Additionally, the surface composition of catalyst materials was conducted using XPS to analyze the and oxidation state of copper nanoparticles on the surface of the carbon support. Deconvolution of the N1s spectra shows the difference in nitrogen species on the different materials (NMC-2 and NMC-7) before and after adding $\mathrm{Cu}$ as shown in Figure 7.
The peaks are typically attributed to 4 different types of nitrogen corresponding to pyridinic-N (N1 $398.2 \mathrm{eV})$, pyrrolic$\mathrm{N}(\mathrm{N} 2399.9 \mathrm{eV})$, quaternary-N (N3 $400.7 \mathrm{eV})$ and pyridine $\mathrm{N}$-oxide (N4 402.7eV) for NMC-7 [20] $\mathrm{Cu}$ loading on the mesoporous carbon support (NMC-7) results in a significant change in the spectra, see Table S1. Figure 7(b and d) shows that both the $\mathrm{N} 1$ and $\mathrm{N} 2$ peaks shifted by $0.2-1 \mathrm{eV}$ towards higher binding energy. This can be attributed to the strong interaction of $\mathrm{Cu}$ with nitrogen species. ${ }^{[35,36]}$ The interaction of $\mathrm{Cu}$ species with pyridinic- $\mathrm{N}$ results in decrease in the
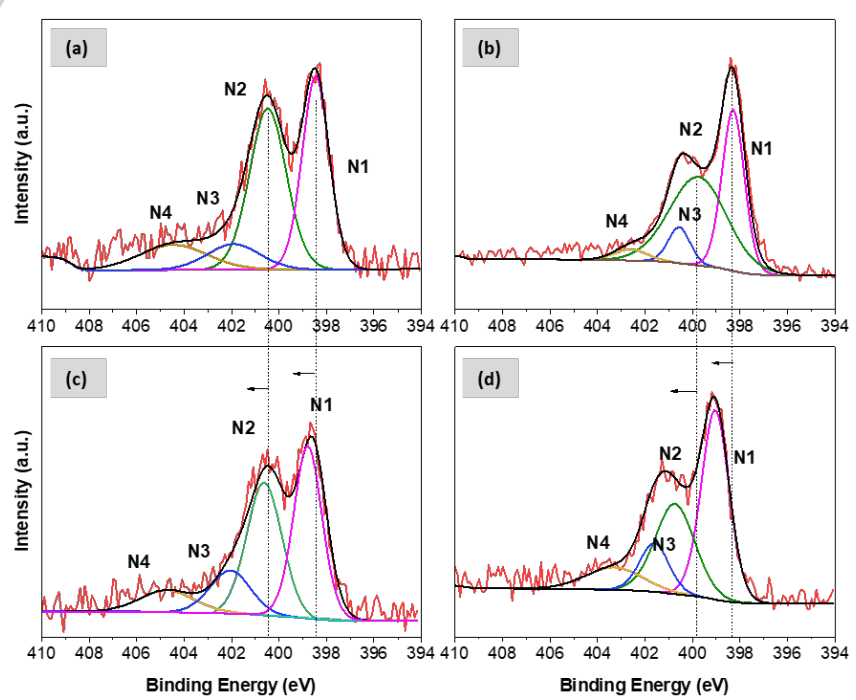

Figure 7. XPS N1s spectra of a) NMC-2, b) NMC-7, c) 3Cu/NMC-2 and d) 3Cu/NMC-7. 

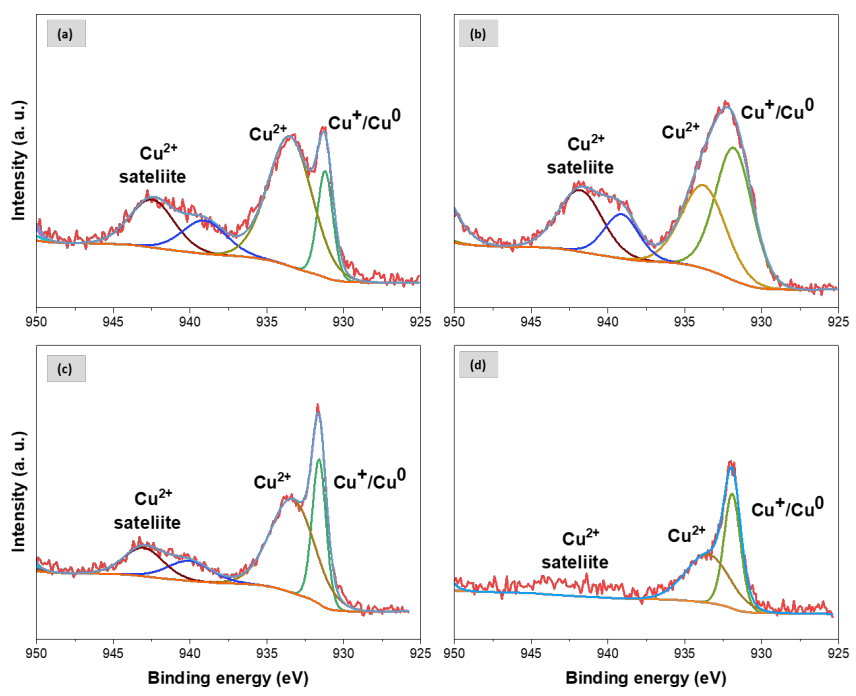

Figure 8. XPS Cu $2 p_{3 / 2}$ spectra of a) $3 C u / A C$, b) $3 C u / N M C-0$, c) $3 C u / N M C-2$ and d) $3 \mathrm{Cu} / \mathrm{NMC}-7$.

relative intensity of $\mathrm{N} 2$ over $\mathrm{N} 3$ after impregnating $\mathrm{Cu}$ over NMC-7. This further reinforces the strong interaction between copper and nitrogen in $\mathrm{Cu}$ loaded samples. The interaction of $\mathrm{Cu}$ with NMC-2 resulted in the small decrease in the N2 and N3 peaks. These factors could attribute to the effect of $\mathrm{N}$-doping on $\mathrm{Cu}$. ${ }^{[20,37]}$

Figure 8 shows the XPS analysis of the $\mathrm{Cu} 2 \mathrm{p}_{3 / 2}$ photopeaks of $3 \mathrm{Cu} / \mathrm{NMCs}$ and $3 \mathrm{Cu} / \mathrm{AC}$. The materials $3 \mathrm{Cu} / \mathrm{NMC}-2$ and $3 \mathrm{Cu} / \mathrm{NMC}-7$ showed a narrow $\mathrm{Cu}^{+} / \mathrm{CuO}$ peaks in XPS and the intensity of $\mathrm{Cu}^{2+}$ satellite peak was less in both samples. However, the samples $3 \mathrm{Cu} / \mathrm{AC}$ and $3 \mathrm{Cu} / \mathrm{NMC}-0$ showed broad and large $\mathrm{Cu}^{2+}$ satellite peak. The results show a strong interaction of $\mathrm{Cu}$ and $\mathrm{N}$ species in $\mathrm{N}$ doped catalysts. Moreover, the $\mathrm{Cu}^{2+}$ satellite peak around $942 \mathrm{eV}$ was negligibly small for 3Cu/NMC-7, which supports the interaction of $\mathrm{Cu}$ and nitrogen in 3Cu/NMC-7. [20,14,38] Additionally, Cu LMM spectra were analyzed, and the spectra are shown in Figure S7. 3Cu/NMC-0, 3Cu/NMC-2 and $3 \mathrm{Cu} / \mathrm{AC}$ had broad peaks in the $\mathrm{Cu}^{+}, \mathrm{Cu}^{0}$ region. Unfortunately, the intensity of Cu LMM spectra were too weak to distinguish between $\mathrm{Cu}^{+}$or $\mathrm{Cu}^{0}$. [39]

The surface content of $\mathrm{C}, \mathrm{N}, \mathrm{O}$ and $\mathrm{Cu}$ in $3 \mathrm{Cu} / \mathrm{NMC}-0$, 3Cu/NMC-2, 3Cu/NMC-7 and 3Cu/AC based on XPS are given in the Table 3 . The data $(\mathrm{C}$ and $\mathrm{N})$ are in good

Table 3. XPS Data for as-synthesized materials..

\begin{tabular}{lcccc}
\hline Catalyst & $\begin{array}{c}\text { Carbon } \\
(\%)\end{array}$ & $\begin{array}{c}\text { Oxygen } \\
\mathbf{( \% )}\end{array}$ & $\begin{array}{c}\text { Nitrogen } \\
\mathbf{( \% )}\end{array}$ & $\begin{array}{c}\text { Copper } \\
(\%)\end{array}$ \\
\hline 3Cu/AC & 92.3 & 6.7 & 0 & 1.0 \\
$3 \mathrm{Cu} / \mathrm{NMC}-0$ & 82.4 & 16.4 & 0 & 1.2 \\
$3 \mathrm{Cu} / \mathrm{NMC}-2$ & 88.6 & 8.8 & 1.5 & 1.1 \\
$3 \mathrm{Cu} / \mathrm{NMC}-7$ & 87.8 & 5.3 & 6.8 & 0.1 \\
\hline
\end{tabular}

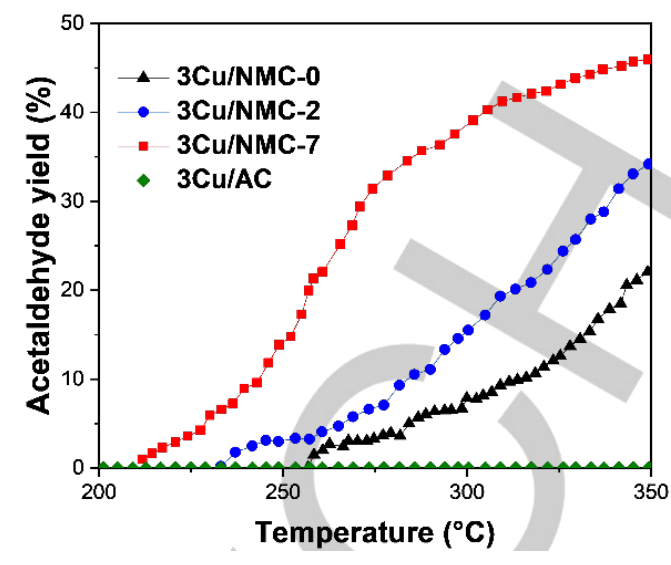

Figure 9. Effect of temperature on the catalytic activity for $3 \mathrm{Cu} / \mathrm{AC}$, $3 \mathrm{Cu} / \mathrm{NMC}-0$, 3Cu/NMC-2 and 3Cu/NMC-7 using $10 \%$ ethanol as reactant feed

agreement with the expected composition from the mesoporous carbon precursors used in the synthesis. All materials showed characteristic peaks of copper on the surface of the impregnated catalysts. However, the results showed a lower surface concentration of $\mathrm{Cu}$ on NMC-7 confirming higher encapsulation of copper nanoparticles by mesoporous carbon support. XPS data for all as-synthesized catalysts are given in Table S2 and S3.

Catalytic activity test: The catalysts were tested for the dehydrogenation of bioethanol $(10 \%$ ethanol $+90 \%$ water reaction feed) at a gas hourly space velocity, GHSV $=21250$ $\mathrm{h}^{-1}$. Figure 9 shows the yield of acetaldehyde against temperature for as-synthesized catalysts and $3 \mathrm{Cu} / \mathrm{AC}$. As shown in the figure, the commercial $\mathrm{Cu}$ catalyst $3 \mathrm{Cu} / \mathrm{AC}$ was completely inactive and did not show any catalytic activity for the dehydrogenation reaction. We speculate that the lack of activity of $3 \mathrm{Cu} / \mathrm{AC}$ was due to the fast oxidation of exposed copper sites or by steam-induced sintering of $\mathrm{Cu}$ nanoparticles. [40,41] The yield of acetaldehyde for all synthesized catalysts increased with the temperature. $3 \mathrm{Cu} / \mathrm{NMC}-7$ showed a significantly higher acetaldehyde yield than $3 \mathrm{Cu} / \mathrm{NMC}-0$ and $3 \mathrm{Cu} / \mathrm{NMC}-2$, which demonstrates the positive effect of nitrogen content and/or the small size of copper nanoparticles on ethanol conversion. To estimate the possible influence of pore diffusion on the reaction rate we used the Weisz-Prater criteria as shown in Table S4. Since the Weisz modulus was significantly below 1 , we concluded that extent of internal diffusion limitation was negligible.

Figure $\mathrm{S} 8$ shows the catalytic activity results for all other catalysts, including $1 \mathrm{Cu} / \mathrm{NMC}-2,1 \mathrm{Cu} / \mathrm{NMC}-7,8 \mathrm{Cu} / \mathrm{NMC}-0$, $8 \mathrm{Cu} / \mathrm{NMC}-2$ and $8 \mathrm{Cu} / \mathrm{NMC}-7$. In general, the yield of acetaldehyde increased with the temperature and reaches up to $57 \%$ yield of acetaldehyde at $350{ }^{\circ} \mathrm{C}$ for $1 \mathrm{Cu} / \mathrm{NMC}-7$ and $48 \%$ yield of acetaldehyde for $1 \mathrm{Cu} / \mathrm{NMC}-2$. Above $99 \%$ selectivity towards acetaldehyde was observed for all catalysts irrespective of the $\mathrm{N}$-content of the ordered mesoporous carbon support. Table S5 summarizes the conversion of ethanol for different catalysts at $350{ }^{\circ} \mathrm{C}$. Furthermore, Figure S9 compares the catalytic activity of $3 \mathrm{Cu} / \mathrm{NMC}-7$ carbonized at 600,700 and $800{ }^{\circ} \mathrm{C}$, respectively. $3 \mathrm{Cu} / \mathrm{NMC}-7$ carbonized at $600{ }^{\circ} \mathrm{C}$ and $700{ }^{\circ} \mathrm{C}$ 


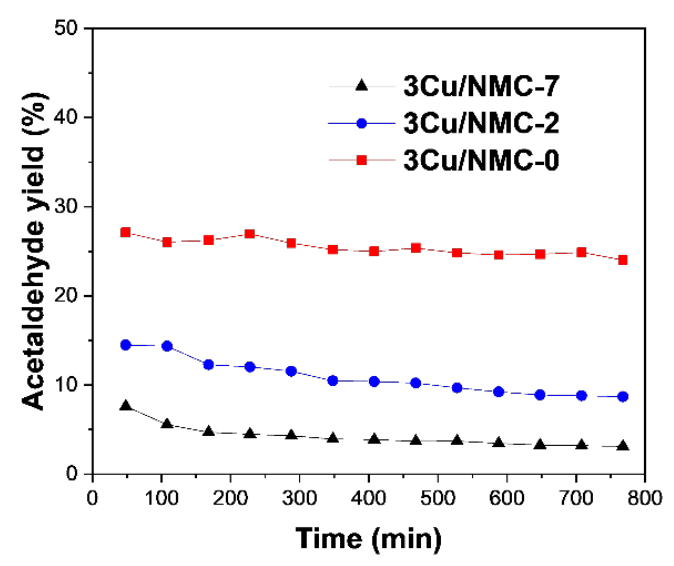

Figure 10 . Stability test at $260{ }^{\circ} \mathrm{C}$ for as-synthesized catalysts with $10 \%$ ethanol feed

exhibited similar activity towards ethanol conversion, while the material carbonized at $800{ }^{\circ} \mathrm{C}$ showed less activity due to the decrease in nitrogen content. These results indicate that both the surface area and the nitrogen content has a significant effect on the catalytic activity. The catalytic activity was investigated using pure ethanol under similar GHSV and the results are shown in Figure S10. The as-synthesized catalysts showed identical catalytic performance as that of $10 \%$ ethanol whereas $3 \mathrm{Cu} / \mathrm{AC}$ showed some ethanol conversion from $260{ }^{\circ} \mathrm{C}$.

Figure 10 shows the stability of $3 \mathrm{Cu} / \mathrm{NMC}-0,3 \mathrm{Cu} / \mathrm{NMC}-2$ and $3 \mathrm{Cu} / \mathrm{NMC}-7$ tested at $260{ }^{\circ} \mathrm{C}$ for 800 minutes. All catalyst showed high selectivity above $99 \%$ throughout the reaction interval. The catalyst $3 \mathrm{Cu} / \mathrm{NMC}-7$ retained around $93 \%$ of its initial activity even after 800 minutes whereas the catalysts $3 \mathrm{Cu} / \mathrm{NMC}-2$ and $3 \mathrm{Cu} / \mathrm{NMC}-0$ retained $68 \%$ and $40 \%$ of the initial activity, respectively. The high stability of $3 \mathrm{Cu} / \mathrm{NMC}-7$ is possibly due to the small and highly dispersed copper nanoparticles combined with high nitrogen content present in the catalyst. $3 \mathrm{Cu} / \mathrm{NMC}-7$ also showed higher stability when tested at higher temperature $\left(320^{\circ} \mathrm{C}\right)$ as shown in Figure $\mathrm{S} 11(\mathrm{a})$. The stability test is also conducted with pure ethanol at the same flowrate (GHSV $=21250 \mathrm{~h}^{-1}$ ) using $3 \mathrm{Cu} / \mathrm{AC}$ and $3 \mathrm{Cu} / \mathrm{NMC}-7$. Figure $\mathrm{S} 11(\mathrm{~b})$ shows the stability test of $3 \mathrm{Cu} / \mathrm{NMC}-7$ as compared to $3 \mathrm{Cu} / \mathrm{AC}$. The higher stability of 3Cu/NMC-7 strengthens the evidence for a strong stabilization effect of doped nitrogen against sintering of copper nanoparticles. Stability of the catalysts with $8 \mathrm{wt} \% \mathrm{Cu}$ using $8 \mathrm{Cu} / \mathrm{NMC}-7$ and $8 \mathrm{Cu} / \mathrm{NMC}-2$ are also tested at $260{ }^{\circ} \mathrm{C}$
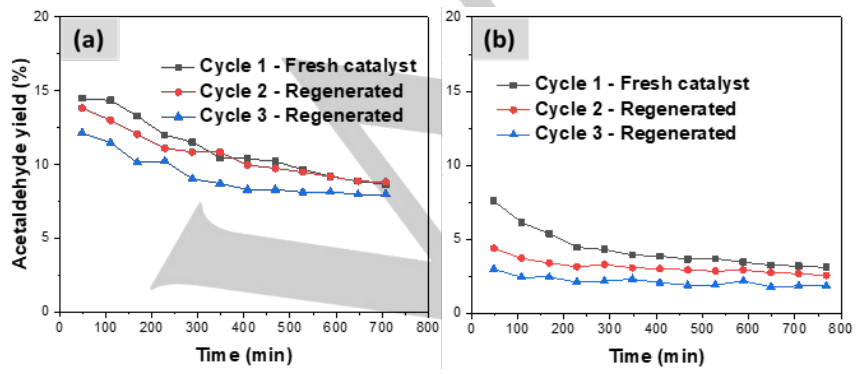

Figure 11. Reusability tests of catalysts a) 3Cu/NMC-2 and b) 3Cu/NMC-0. with the results shown in Figure S11(c). 8Cu/NMC-7 showed good stability and it retained nearly $80 \%$ of its initial activity after 800 minutes. In general, the loss of activity was less in the case of catalysts with high nitrogen content and can attribute to the strong $\mathrm{Cu}$ and support interaction.

The reusability of the catalysts was tested by regenerating the catalysts using an in-situ reduction at 450 ${ }^{\circ} \mathrm{C}$ for 2 hours under $\mathrm{H}_{2}$. The regenerated catalysts were then subjected to the same catalytic test. Figure 11(a) and 11(b) show the re-usability of $3 \mathrm{Cu} / \mathrm{NMC}-2$ and $3 \mathrm{Cu} / \mathrm{NMC}-0$, respectively. The regenerated catalyst $3 \mathrm{Cu} / \mathrm{NMC}-2$ showed $95 \%$ and $84 \%$ of initial activity over fresh catalyst in cycle 2 and cycle 3. For comparison, 3Cu/NMC-0 showed acetaldehyde yields of $60 \%$ and $37 \%$ from its initial activity over fresh catalyst in cycle 2 and cycle 3 , respectively. The reusability results for the catalyst $3 \mathrm{Cu} / \mathrm{NMC}-7$ are shown in Figure S11(d).

Figure 12 shows the TEM images of the spent catalysts analyzed after the stability tests. The TEM image of $3 \mathrm{Cu} / \mathrm{NMC}-0$ showed both small and big particles with an average particle size $15.4 \mathrm{~nm}$. In contrast, the TEM images of $3 \mathrm{Cu} / \mathrm{NMC}-7$ with the highest content of $\mathrm{N}$, showed welldispersed nanoparticles and no significant change in the particle size distribution after the catalytic test, see Figure 13. This shows that the copper nanoparticles are effectively confined in the mesoporous carbon of 3Cu/NMC-7. The average size of the $\mathrm{Cu}$ nanoparticles in $3 \mathrm{Cu} / \mathrm{AC}$ was increased from $22.1 \mathrm{~nm}$ to $34 \mathrm{~nm}$ after the stability test and shows higher migration of $\mathrm{Cu}$ nanoparticles in $3 \mathrm{Cu} / \mathrm{AC}$ as compared to the as-synthesized catalysts. Figure $\mathrm{S} 12$ shows the particle size distribution of $3 \mathrm{Cu} / \mathrm{NMC}-0,3 \mathrm{Cu} / \mathrm{NMC}-2$ and $3 \mathrm{Cu} / \mathrm{AC}$ after the stability test.
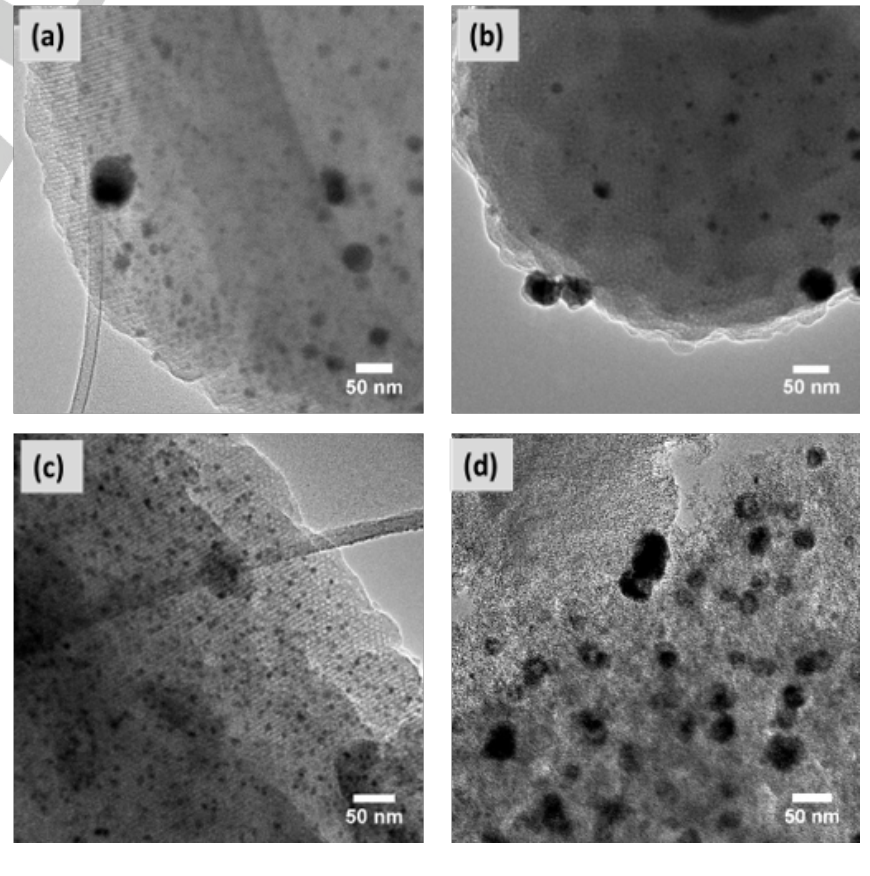

Figure 12. TEM Image after stability test for a) 3Cu/NMC-0, b) 3Cu/NMC-2, c) $3 \mathrm{Cu} / \mathrm{NMC}-7$ and d) 3Cu/AC. 

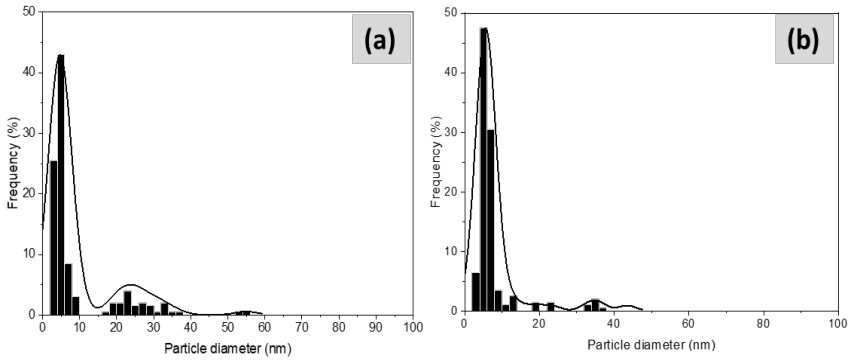

Figure 13. Particle size distribution histogram of $3 \mathrm{Cu} / \mathrm{NMC}-7$ before and after the catalytic activity test

Figure 14 shows the XRD pattern of the catalysts after the stability test. Compared to the XRD patterns of the fresh catalysts, the intensity of $\mathrm{Cu}(111)$ diffraction peak was increased. The intensity of $\mathrm{Cu}(111)$ peak increased in the order $3 \mathrm{Cu} / \mathrm{NMC}-7<3 \mathrm{Cu} / \mathrm{NMC}-2 \approx 3 \mathrm{Cu} / \mathrm{AC}<3 \mathrm{Cu} / \mathrm{NMC}-0$. The results are a clear indication of the confinement of small nanoparticles in ordered mesoporous carbon combined with stabilizing effect of copper nanoparticles by nitrogen doping in $3 \mathrm{Cu} / \mathrm{NMC}-7$. This stabilization effect due to nitrogen doping is not found in $3 \mathrm{Cu} / \mathrm{NMC}-0$ resulting in the sintering of copper nanoparticles during the reaction, a well-known reason for deactivation of copper nanoparticles in dehydrogenation reaction of ethanol. ${ }^{[42,43]}$ The appearance of the typical diffraction peak of $\mathrm{Cu}_{2} \mathrm{O}(111)$ further support that surface oxidation may contribute to the deactivation of the catalysts. In line with the previous results, the effect is most significant for the catalysts with no or low nitrogen content.

Figure 15 shows the Arrhenius plots for the catalysts with $3 \mathrm{wt} \% \mathrm{Cu}$ loading. The apparent activation energies of catalysts are around $86.1,81.6$ and $81.2 \mathrm{~kJ} / \mathrm{mol}$ for 3Cu/NMC-0, 3Cu/NMC-2 and 3Cu/NMC-7, respectively. This indicates that the $\mathrm{N}$-doping has no effect on the rate-limiting step and can be related to the dispersion of the $\mathrm{Cu}$ nanoparticles. The lowering of the light-off temperature is expected to be caused by an increase in active sites, due to the higher $\mathrm{Cu}$ dispersion, which provide more active sites for

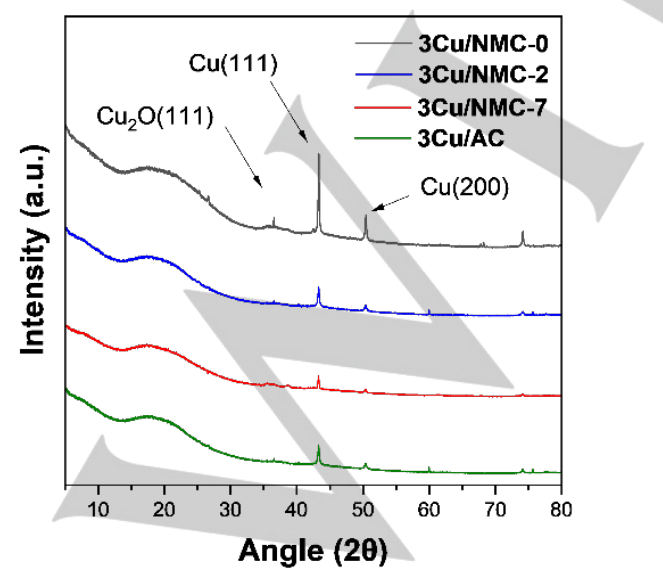

Figure 14. XRD patterns after stability test.

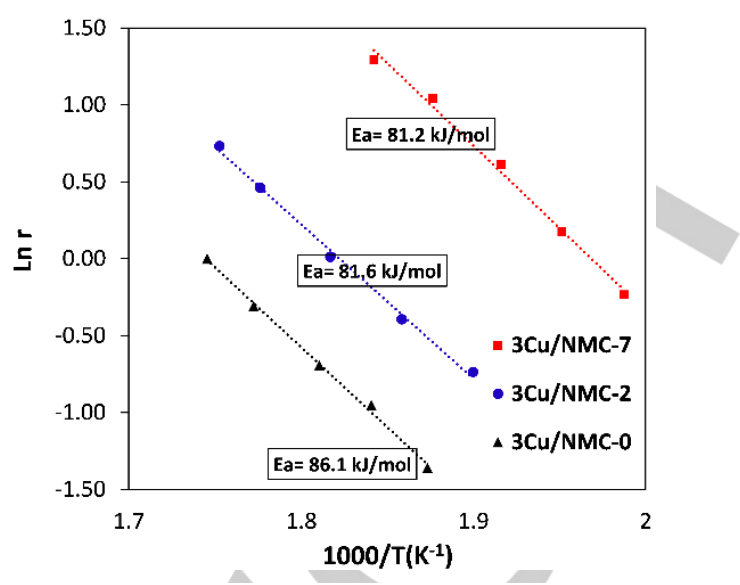

Figure 15. Arrhenius plot of reaction rate over temperature of as-synthesized catalyst.

the dehydrogenation to occur. At $260{ }^{\circ} \mathrm{C}$, the site-time yield (STY) of the catalysts are 14.6, 39.1 and 175 $\mathrm{mol}_{\text {acetaldehyde }} / \mathrm{mol}_{\mathrm{Cu}} / \mathrm{h}$ for 3Cu/NMC-0, 3Cu/NMC-2 and $3 \mathrm{Cu} / \mathrm{NMC}-7$, respectively. The catalyst $3 \mathrm{Cu} / \mathrm{NMC}-7$ was also tested at a high GHSV 26500 and $45450 \mathrm{~h}^{-1}$ where STY increased to 202 and $265 \mathrm{~mol}_{\text {acetaldehyde }} / \mathrm{mol}_{\mathrm{Cu}} / \mathrm{h}$. To the best of our knowledge, catalytic activity of 3Cu/NMC-7 showed best STY of similar catalysts reported. Table S6 shows comparison on activity of catalysts in recently published literature.

In order to investigate the effect of nitrogen in the reaction mechanism, we studied the mechanism on the surface of catalysts by in-situ DRIFTS at temperatures between 50 to $350{ }^{\circ} \mathrm{C}$. The in-situ DRIFTS studies were conducted on $3 \mathrm{Cu} / \mathrm{NMC}-7$ and $3 \mathrm{Cu} / \mathrm{NMC}-2$. The in-situ DRIFT spectra of $3 \mathrm{Cu} / \mathrm{NMC}-7$ and $3 \mathrm{Cu} / \mathrm{NMC}-0$ are given in Figure S13(a) and (b). The detailed explanation on major observations from the spectra are given the supporting info. With the spectra of both 3Cu/NMC-7 and 3Cu/NMC-0 showing similar behavior through the temperature range, we can confirm that dehydrogenation of ethanol to acetaldehyde follows similar reaction mechanism with ethoxy formation as an intermediate. Furthermore, nitrogen has no role in defining the mechanism of dehydrogenation reaction.

\section{Conclusion}

In this work, we report the synthesis of an efficient and highly selective catalyst for the conversion of bioethanol to acetaldehyde via selective dehydrogenation. The catalyst is comprised of $\mathrm{Cu}$ nanoparticles supported on $\mathrm{N}$-doped ordered mesoporous carbon prepared by carbonization of a templated polymer by increasing the amount of $\mathrm{N}$ in the polymer precursors, we were able to increase the amount of $\mathrm{N}$ in the carbon support from 0 to $7 \%$. The ordered mesoporous carbon with the highest amount of $\mathrm{N}$ resulted in the highest $\mathrm{Cu}$ loading and, consequently, the highest catalytic activity and stability. We contribute this effect to increased metal-support interactions. Under the given reaction condition, $3 \mathrm{Cu} / \mathrm{NMC}-7$ resulted in a high yield of 
acetaldehyde with a STY of $175 \mathrm{~mol}$ acetaldehyde $/ \mathrm{mol}_{\mathrm{cu}} / \mathrm{h}$, more than $99 \%$ selectivity. Furthermore, the $\mathrm{N}$-doped carbon prevent deactivation by surface oxidation or steam induced sintering in the presence of water. In situ DRIFTS studies confirm that the formation of acetaldehyde occurs via an ethoxy intermediate independent but does not indicate that the $\mathrm{N}$-doping activates the ethanol or change the ratedetermining step.

\section{Experimental section}

Materials: All chemicals and materials are used as received from Sigma-Aldrich with no further purification. Pluronic ${ }^{\circledR} \mathrm{F}-127\left(\mathrm{M}_{\mathrm{n}} \sim 12\right.$ 500), 3-aminophenol (3AMP, 98\%), hexamethylenetetramine (HMTA, 99\%), formaldehyde (FA, 37\%), resorcinol ( $\geq 99.0 \%)$ ammonia $(28 \%$ aqueous solution, $\geq 99.99 \%)$, sodium carbonate $(\geq 99.0 \%)$, ethanol (EtOH $>99.8 \%)$, copper on activated carbon (3 wt $\%, 3 \mathrm{Cu} / \mathrm{AC})$, copper nitrate hemipentahydrate $\left(\mathrm{Cu}\left(\mathrm{NO}_{3}\right)_{2} \cdot 2.5 \mathrm{H}_{2} \mathrm{O}\right.$, $\geq 99.99 \%$ ).

Synthesis of NMC-0: $\mathrm{F}-127(8.8 \mathrm{~g})$ is dissolved in deionized water $(208 \mathrm{~mL})$ at room temperature followed by adding resorcinol $(4.4 \mathrm{~g})$ and formaldehyde $37 \%(8.85 \mathrm{~mL})$ by stirring at room temperature. $\mathrm{Na}_{2} \mathrm{CO}_{3}(20 \mathrm{mg})$ is then added and stirred at $80^{\circ} \mathrm{C}$ for 24 hours. The precipitate is collected by centrifugation and washed with deionized water three times. The reddish-brown product is dried at $80{ }^{\circ} \mathrm{C}$ overnight and then carbonized at $600{ }^{\circ} \mathrm{C}$ in argon atmosphere for 3 hours with a heating ramp of $1^{\circ} \mathrm{C} / \mathrm{min}$.

Synthesis of NMC-2: F-127 $(8.8 \mathrm{~g})$ is dissolved in deionized water $(208 \mathrm{~mL})$ at room temperature followed by adding resorcinol $(4.4 \mathrm{~g})$ and hexamethylenetetramine $(2.8 \mathrm{~g})$ by stirring at room temperature. $\mathrm{NH}_{3}$ solution $28 \%(8 \mathrm{ml})$ is then added and the mixture is stirred at $80^{\circ} \mathrm{C}$ for 24 hours. The precipitate is collected by centrifugation and washed with deionized water three times. The reddish-brown product is dried at $80^{\circ} \mathrm{C}$ overnight and then carbonized at $600^{\circ} \mathrm{C}$ under argon atmosphere for 3 hours with a heating ramp of $1^{\circ} \mathrm{C} / \mathrm{min}$.

Synthesis of NMC-7: The synthesis of NMC-7 was based on a modified version of the procedure reported by Guozhu Shen. ${ }^{[25]} \mathrm{F}_{-}$ $127(8.8 \mathrm{~g})$ is dissolved in deionized water $(208 \mathrm{~mL})$ at room temperature followed by adding 3-aminophenol $(4.4 \mathrm{~g})$ and hexamethylenetetramine $(2.8 \mathrm{~g})$ by stirring at room temperature. $\mathrm{NH}_{3}$ solution $28 \%(8 \mathrm{ml})$ is then added and the mixture is stirred at $80{ }^{\circ} \mathrm{C}$ for 24 hours. The precipitate is collected by centrifugation and washed with deionized water three times. The reddish-brown product is dried at $80^{\circ} \mathrm{C}$ overnight and then carbonized at $600^{\circ} \mathrm{C}$ under argon atmosphere for 3 hours with a heating ramp of $1^{\circ} \mathrm{C} / \mathrm{min}$.

The same procedure is repeated to prepare two additional NMC-7 samples with carbonisation temperatures of $700{ }^{\circ} \mathrm{C}$ and 800 ${ }^{\circ} \mathrm{C}$, respectively.

Synthesis of $\mathrm{xCu} / \mathrm{NMC}-\mathrm{y}$ : The carbon-supported catalysts are prepared by incipient wetness impregnation using $\mathrm{Cu}\left(\mathrm{NO}_{3}\right)_{2}$ as metal precursor and ethanol as solvent. The appropriate amount of $\mathrm{Cu}\left(\mathrm{NO}_{3}\right)_{2} \cdot 2.5 \mathrm{H}_{2} \mathrm{O}$ is mesoporous carbon support $(0.485 \mathrm{~g})$ followed by thorough mixing. The resulting material is reduced under a flow of pure $\mathrm{H}_{2}$ at $450{ }^{\circ} \mathrm{C}$ for 2 hours with a heating ramp of $5{ }^{\circ} \mathrm{C} / \mathrm{min}$. The same procedure is used to prepare catalysts with 1,3 and $8 \mathrm{wt} \%$ of
$\mathrm{Cu}$. The catalysts are named $\mathrm{xCu} / \mathrm{NMC}-\mathrm{y}$, where $\mathrm{x}$ represent the $\mathrm{Cu}$ loading and $y$ represent the weight percentage of nitrogen in the mesoporous carbon support.

Catalytic activity test: The catalysts were tested in a fixed-bed quartz tubular reactor under atmospheric pressure. $50 \mathrm{mg}$ of the catalyst (1Cu/NMC-7) without fractionation (approx. particle size < $100 \mu \mathrm{m}$ ) was mixed with fractionated quartz $(300-355 \mu \mathrm{m})$ and loaded in the reactor. The catalyst was then reduced using $10 \% \mathrm{H}_{2}$ in $\mathrm{N}_{2}$ gas (100 $\mathrm{ml} / \mathrm{min}$ ) for 90 minutes at $450{ }^{\circ} \mathrm{C}$ a heating ramp of $5^{\circ} \mathrm{C} / \mathrm{min}$ under atmospheric pressure. The gas was then switched to pure N2 (50 $\mathrm{ml} / \mathrm{min}$ ) and the temperature was then lowered to $350{ }^{\circ} \mathrm{C}$. An aqueous solution of $10 \%$ ethanol was introduced using a micro pump and the preheated gas mixture is then passed through the reactor with a gas hourly space velocity (GHSV) $21250 \mathrm{~h}^{-1}$. The conversion and selectivity were quantified using an online GC equipped with a flame ionization detector (FID). Gas samples from the reaction outlet were collected and analyzed using GC-MS. The procedure was repeated with pure ethanol. Ethanol flow was adjusted using a syringe pump to get the GHSV similar to the experiment with $10 \%$ ethanol.

Characterization: X-ray powder diffraction (XRD) patterns are recorded using a Huber G670 powder diffractometer and Cu-Ka radiation $(\lambda=1.54056 \mathrm{~nm})$. The diffraction patterns are recorded from $2 \theta=5-100^{\circ}$. A Micrometrics 3Flex physisorption instrument is used to record the nitrogen adsorption-desorption isotherm at $77 \mathrm{~K}$. The total surface area is determined by the BET method, the total pore volume is determined from a single-point read at $0.95 \mathrm{p} / \mathrm{p}_{0}$, the microporous volume is calculated from the t-plot and the pore-size distribution are calculated according to the BJH method. Prior to physisorption analysis, the samples are degassed at $200{ }^{\circ} \mathrm{C}$ in vacuum for overnight. Scanning electron microscopy (SEM) analysis is performed using a QUANTA FEG 400 SEM instrument and transmission electron microscopy (TEM) analysis is performed using a Tecnai T20 instrument operated at $200 \mathrm{kV}$. Prior to the analysis, the samples are directly dispersed on a lacey carbon grid. High-angle annular dark-field scanning transmission electron microscopy (HAADF-STEM) analysis is performed on an aberration-corrected JEOL ARM300CF instrument operated at $300 \mathrm{kV}$. X-ray photoelectron spectroscopy (XPS) is carried out using an angleresolved XPS instrument Thermo Scientific ${ }^{\mathrm{TM}}$ K-Alpha ${ }^{\mathrm{TM}}$ spectrometer. All XPS spectra were collected on reduced catalysts which were exposed to air during transfer sample preparation.

The Cu loading is determined by inductively coupled plasma optical emission spectroscopy using Thermo Scientific ${ }^{\text {TM }}$ iCAP ${ }^{\text {TM }} 7200$ ICPOES. Samples $(20 \mathrm{mg})$ are first treated with $20 \mathrm{~mL}$ of aqua regia to dissolve the $\mathrm{Cu}$ and then diluted accordingly. The concentration is determined from a calibration line made from a commercial ICP standard. The elemental composition of the mesoporous $\mathrm{N}$-doped carbon support is determined with a Thermo scientific FlashSmart ${ }^{\mathrm{TM}}$ Elemental Analyzer. The reduction temperature of the supported $\mathrm{Cu}$ nanoparticle are analyzed by temperature-programmed reduction $\left(\mathrm{H}_{2}\right.$-TPR) using a Micromeritics Autochem-Il instrument. Samples are heated up to $500{ }^{\circ} \mathrm{C}$ at a ramp of $10^{\circ} \mathrm{C}$ per minute in $5 \% \mathrm{H}_{2}$ in $\operatorname{Ar}$ gas flow ( $50 \mathrm{~mL} / \mathrm{min}$ ). The $\mathrm{H}_{2}$ consumption is monitored using a thermal conductivity detector (TCD). A cold trap with dry ice is used to trap the water formed during the reduction with $\mathrm{H}_{2}$. Diffuse reflectance infrared Fourier transform spectroscopy (DRIFTS) is performed on a Thermo Nicolet 6700 FTIR using a reactor and Praying Mantis diffuse 
reflectance accessory from Harrick Scientific Products. Prior to the analysis, the catalysts are mixed with $\mathrm{KBr}$. The catalyst is then reduced at a temperature of $450{ }^{\circ} \mathrm{C}$ for 2 hours followed by a collection of background IR spectra under a flow of $\mathrm{N}_{2}$. After cooling to $50{ }^{\circ} \mathrm{C}$ the $\mathrm{N}_{2}$ is bubbled through ethanol to introduce the reactant into the reactor. IR spectra are then collected in a temperature range between $50-300{ }^{\circ} \mathrm{C}$. Spectra are recorded continuously every 30 seconds until saturation of ethanol on the surface of the catalysts. The flow of ethanol is stopped afterwards followed by passing $\mathrm{N}_{2}$ on the catalyst surface. Spectra are recorded for every 30 seconds for around 20 to 30 minutes during this process. The same procedure is repeated for temperature $100,200,300$ and $350^{\circ} \mathrm{C}$. Spectra of pure ethanol on $\mathrm{KBr}$ pellet is also recorded in order to differentiate between the DRIFTS peaks of gaseous ethanol and the ethanol on catalyst surface.

\section{Acknowledgements}

We thank the Independent Research Fund Denmark (grant no. 5054-00119 and no. 6111- 00237), Villum Fonden (Grant No. 13158), and Haldor Topsøe A/S for financial support. STEM HAADF and EDX images were acquired at the Diamond Light Source, UK, at their electronic Physical Science Imaging Centre (ePSIC).

Keywords: Dehydrogenation $\cdot \mathrm{N}$-doping $\cdot$ Heterogeneous catalysis $\cdot \mathrm{DRIFTS} \cdot \mathrm{Cu}$ nanoparticles

[1] C. H. Christensen, B. Jørgensen, J. Rass-Hansen, K. Egeblad, R. Madsen, S. K. Klitgaard, S. M. Hansen, M. R. Hansen, H. C. Andersen, A. Riisager, Angew. Chemie - Int. Ed. 2006, 45, 4648-4651.

[2] R. Harun, M. K. Danquah, G. M. Forde, J. Chem. Technol. Biotechnol. 2010, 85, 199-203.

[3] J. Mielby, J. O. Abildstrøm, F. Wang, T. Kasama, C. Weidenthaler, S. Kegnæs, Angew. Chemie - Int. Ed. 2014, 53, 12513-12516.

[4] Y. Y. Gorbanev, S. Kegnæs, C. W. Hanning, T. W. Hansen, A. Riisager, ACS Catal. 2012, 2, 604-612.

[5] M. Y. Li, W. D. Lu, L. He, F. Schüth, A. H. Lu, ChemCatChem 2019, 11 481-487.

[6] M. Kuwahara, M. Nishioka, M. Yoshida, K. ichi Fujita, ChemCatChem 2018, 3636-3640.

[7] G. M. Lari, K. Desai, C. Mondelli, J. Pérez-Ramírez, Catal. Sci. Technol. 2016, 6, 2706-2714.

[8] S. Velu, L. Wang, M. Okazaki, K. Suzuki, S. Tomura, Microporous Mesoporous Mater. 2002, 54, 113-126.

[9] Q. N. Wang, L. Shi, W. Li, W. C. Li, R. Si, F. Schüth, A. H. Lu, Catal. Sci. Technol. 2018, 8, 472-479.

[10] M. Ohira, H. Liu, D. He, Y. Hirata, M. Sano, T. Suzuki, T. Miyake, J. Japan Pet. Inst. 2018, 61, 205-212.

[11] F. Zaccheria, N. Ravasio, R. Psaro, A. Fusi, Chem. - A Eur. J. 2006, 12 6426-6431.

[12] J. C. Serrano-Ruiz, R. Luque, A. Sepúlveda-Escribano, Chem. Soc. Rev. 2011, 40, 5266-5281.

[13] J. Ob-eye, P. Praserthdam, B. Jongsomjit, Catalysts 2019, 9, 66.

[14] M. V. Morales, E. Asedegbega-Nieto, B. Bachiller-Baeza, A. GuerreroRuiz, Carbon N. Y. 2016, 102, 426-436.

[15] W. D. Lu, Q. N. Wang, L. He, W. C. Li, F. Schüth, A. H. Lu, ChemNanoMat 2018, 4, 505-509.

[16] C. Wang, G. Garbarino, L. F. Allard, F. Wilson, G. Busca, M. FlytzaniStephanopoulos, ACS Catal. 2016, 6, 210-218.

[17] L. Liu, A. Corma, Chem. Rev. 2018, 118, 4981-5079.
[18] G. Garbarino, P. Riani, M. Villa García, E. Finocchio, V. Sanchez Escribano, G. Busca, Catal. Today 2019, 0-1.

[19] A. B. Laursen, K. T. Højholt, L. F. Lundegaard, S. B. Simonsen, S. Helveg, F. Schüth, M. Paul, J. D. Grunwaldt, S. Kegnœs, C. H. Christensen, et al., Angew. Chemie - Int. Ed. 2010, 49, 3504-3507.

[20] P. Zhang, Q. N. Wang, X. Yang, D. Wang, W. C. Li, Y. Zheng, M. Chen, A. H. Lu, ChemCatChem 2017, 9, 505-510.

[21] S. Kramer, F. Hejjo, K. H. Rasmussen, S. Kegnæs, ACS Catal. 2018, 8, 754-759.

[22] D. A. Bulushev, A. L. Chuvilin, V. I. Sobolev, S. G. Stolyarova, Y. V. Shubin, I. P. Asanov, A. V. Ishchenko, G. Magnani, M. Riccò, A. V. Okotrub, et al., J. Mater. Chem. A 2017, 5, 10574-10583.

[23] G. de Falco, F. Montagnaro, M. Balsamo, A. Erto, F. A. Deorsola, L. Lisi, S. Cimino, Microporous Mesoporous Mater. 2018, 257, 135-146.

[24] Y. Yang, Y. Qian, C. Xu, J. Jiang, X. Chen, Appl. Mech. Mater. 2012, 184-185, 1466-1470.

[25] G. Shen, X. Sun, H. Zhang, Y. Liu, J. Zhang, A. Meka, L. Zhou, C. Yu, 2015, 24041-24048.

[26] R. A. W. Sing, K.S.W., Everet, D. H., Haul, Pure Appl. Chem. 1985, 57, 603-619.

[27] F. Goodarzi, L. Kang, F. R. Wang, F. Joensen, S. Kegnæs, J. Mielby, Chem CatChem 2018, 10, 1566-1570.

[28] M. Thommes, K. Kaneko, A. V. Neimark, J. P. Olivier, F. RodriguezReinoso, J. Rouquerol, K. S. W. Sing, Pure Appl. Chem. 2015, 87, $1051-$ 1069.

[29] P. Zhang, L. Wang, S. Yang, J. A. Schott, X. Liu, S. M. Mahurin, C. Huang, Y. Zhang, P. F. Fulvio, M. F. Chisholm, et al., Nat. Commun. 2017, 8, 110.

[30] X. H. Li, K. Wan, Q. B. Liu, J. H. Piao, Y. Y. Zheng, Z. X. Liang, Cuihua Xuebao/Chinese J. Catal. 2016, 37, 1562-1567.

[31] E. A. Redina, A. A. Greish, I. V. Mishin, G. I. Kapustin, O. P. Tkachenko, O. A. Kirichenko, L. M. Kustov, Catal. Today 2015, 241, 246-254.

[32] R. X. Zhou, X. Y. Jiang, J. X. Mao, X. M. Zheng, Appl. Catal. A Gen. 1997, 162, 213-222.

[33] C. Xia, J. Chen, F. Cui, X. Zhang, H. Kang, Z. Huang, Chem. Mater. 2008 20, 5090-5099.

[34] R. Poreddy, C. Engelbrekt, A. Riisager, Catal. Sci. Technol. 2015, 5 2467-2477.

[35] Y. Xie, C. Zhang, X. He, J. W. Su, T. Parker, T. White, M. Griep, J. Lin Appl. Surf. Sci. 2019, 464, 344-350.

[36] A. Diacon, E. Rusen, A. Mocanu, L. C. Nistor, Sci. Rep. 2017, 7, 10345

[37] Y. Gao, J. Li, L. Wang, et al. Nanotechnology. 2020, 31(5), 055705

[38] J. C. Bauer, G. M. Veith, L. F. Allard, Y. Oyola, S. H. Overbury, S. Dai, ACS Catal. 2012, 2, 2537-2546.

[39] M. Galbiati, A. Stoot, D. Mackenzie, et al. Sci Rep. 2017, 7, 39770

[40] G. Di. M. R. Dabera, M. Walker, A. M. Sanchez, H. J. Pereira, R. Beanland, R. A. Hatton, Nat. Commun. 2017, 8, DOI 10.1038/s41467017-01735-6.

[41] T. Mitsudome, Y. Mikami, K. Ebata, T. Mizugaki, K. Jitsukawa, K. Kaneda, Chem. Commun. 2008, 2, 4804-4806.

[42] E. Santacesaria, G. Carotenuto, R. Tesser, M. Di Serio, Chem. Eng. J. 2012, 179, 209-220.

[43] J. M. Conesa, M. V. Morales, C. López-Olmos, I. Rodríguez-Ramos, A Guerrero-Ruiz, Appl. Catal. A Gen. 2019, 576, 54-64. 


\section{WILEY-VCH}

\section{COMMUNICATION}

\section{Entry for the Table of Contents}
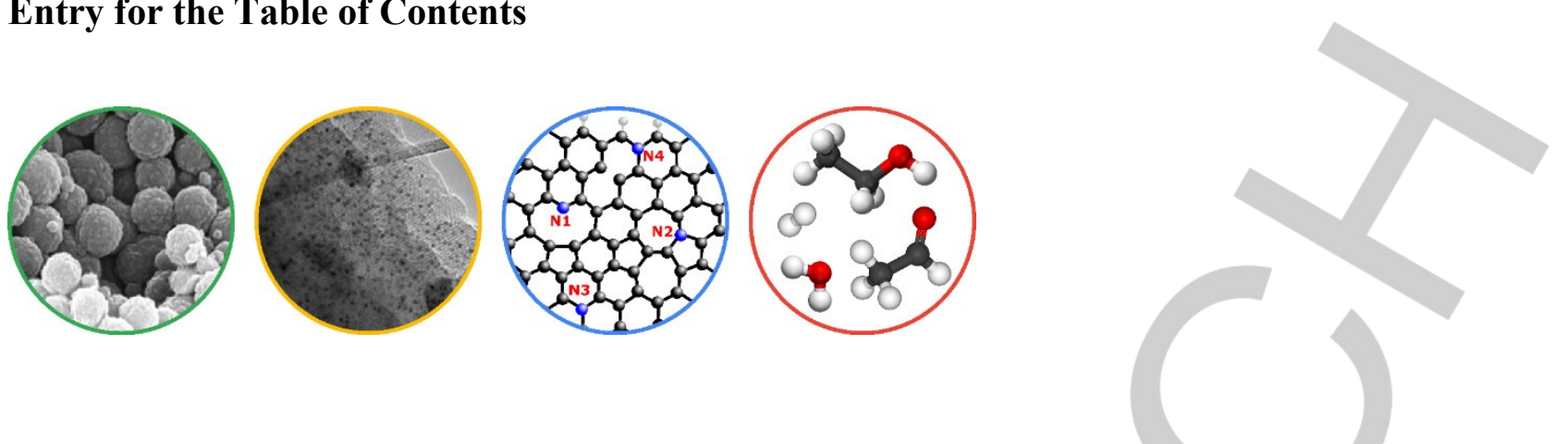

Here, we investigate the catalytic dehydrogenation of bioethanol to acetaldehyde using Cu nanoparticles supported on different $\mathrm{N}$ doped ordered mesoporous carbons. Our study shows thatN-doping has a significant effect on the dispersion of the Cu nanoparticles and that the highest content of $\mathrm{N}$ results in the highest catalytic activity and stability. At $260{ }^{\circ} \mathrm{C}$, the best catalyst results in $>99 \%$ selectivity and a STY of 175 molacetaldehyde/molCu/h.

Institute and/or researcher Twitter usernames: @ChemistryDtu 